\title{
The Role of EUS and EUS-FNA in Detection of Small Sized Liver Metastatic Lesions in Patients with Pancreatic and Gastro-Intestinal Primary Malignancy
}

\author{
HANAN ABDEL HAFEZ, M.D.*; HUSSEIN HASSAN OKASHA, M.D.**; \\ AHMED MOHAMED HASHEM, M.Sc.***; MOHAMED HASSANY, M.D.*** and \\ SAEED M. EL-NAHAAS, M.D.* \\ Endemic Medicine Department and Hepatology Unit*, Internal Medicine Department**, Faculty of Medicine, \\ Cairo University and National Hepatology \& Tropical Medicine Research Institute***, Cairo, Egypt
}

\begin{abstract}
Background: Liver is common site of metastasis. Small liver masses $(<2 \mathrm{~cm})$ are not easily detected by ultrasound or computed tomography. Endosonography allows visualization of liver anatomy.

Aim of Study: To assess usefulness of endosonography and EUS-FNA in detecting small sized liver metastasis; not diagnosed by CT scan during TMN staging of gastro-intestinal and pancreatic malignancy.

Patients and Methods: This prospective comparative study included 92 cases with pancreatic, peri-ampullary and GI malignancies. Patients undergone:

CBC, serum bilirubin, AST, ALT, ALP, GGT, serum protocol albumin, prothrombin concentration, creatinine, AFP and CA19.9, abdominal ultrasound, pancreatic computed tomography scan and endosonography. EUS-FNA and cytological examination were performed in 23 patients.

Results: CT scan detected 27 patients with liver focal lesions, one patient was missed. While EUS detected 27 cases, and also one patient was missed. Among cases diagnosed by EUS, 4 cases were cholangitic abcesses, EUS-FNA was performed in 23 cases, revealing metastatic lesions in 21 patients, benign lesions in 2 patients (focal fat depletion). EUS had $95.45 \%$ sensitivity, $97.14 \%$ specificity, $91.3 \%$ positive predictive value (PPV), 98.55\% negative predictive value (NPV) and $96.74 \%$ accuracy. CT had $95.45 \%$ sensitivity, 91.43\% specificity, $77.78 \%$ PPV, 98.46\% NPV and $92.39 \%$ accuracy. EUS-FNA, had $95.45 \%$ sensitivity, $100 \%$ specificity, $100 \%$ PPV, $98.5 \%$ NPV and $98.91 \%$ accuracy.
\end{abstract}

Conclusions: EUS and EUS-FNA play a significant role in detecting small sized liver metastasis, where EUS and EUSFNA showed a higher diagnostic accuracy compared to that of CT scan.

Key Words: Endosonography-Liver metastasis - Pancreatic malignancy - Gastro-intestinal malignancy.

Correspondence to: Dr. Saeed Mostafa El-Nahaas, E-Mail: saeedmostafa584@ gmail.com

\section{Introduction}

FOCAL hepatic lesions include benign lesions (as hepatic cysts, focal nodular hyperplasia, regenerative nodular hyperplasia, abscess, adenoma or hemangioma), and malignant lesions (as hepatocellular carcinoma, intrahepatic cholangiocarcinoma and metastatic liver disease) [1]

Since the mesenteric veins drain blood from the colon, small bowel, pancreas, and stomach to the liver, this explains that the liver is a common site for metastatic deposits for these organs' primary malignancy [2]. Histologically, pancreatic adenocarcinoma represents the majority of pancreatic cancer cases. Liver is the most common site of metastasis for pancreatic adenocarcinoma [3]. Colorectal cancer (CRC) is the most common gastrointestinal tumor. Similar to pancreatic adenocarcinoma, liver is the most common site of CRC metastases with an incidence of $15 \%-20 \%$ at diagnosis [4]. Also as regard gastric cancer, $35 \%$ of patients have evidence of distant metastases, and $4 \%$ to $14 \%$ have metastatic liver disease, with a very poor prognosis, at time of diagnosis [5]

Endoscopic ultrasound (EUS) is an important diagnostic tool [6]. Due to the close proximity of the transducer to the liver, from the transgastric and transduodenal routes, EUS allows a good visualization of the liver anatomy and its vasculature providing detailed images [7].

Small liver masses $(<2 \mathrm{~cm})$ are not easily accessible by ultrasound or CT guided percutaneous biopsy [8]. In recent review by Srinivasan et al., [1], EUS has shown superiority in detecting small focal hepatic lesions. 
Fuijii-Lau et al., [9] concluded that EUS criteria may help in distinguishing benign from malignant hepatic lesions, and can guide the decision to perform EUS-FNA on a liver mass or not.

\section{Aim of study:}

To assess usefulness of endosonography and EUS-FNA in detecting small sized liver metastasis; not diagnosed by CT scan during TMN staging of gastro-intestinal and pancreatic malignancy.

\section{Patients and Methods}

\section{Study design:}

This prospective comparative study was conducted on 92 cases with suspected or confirmed pancreatic, periampullary or GI malignancies. The patients were recruited from Kasr Al-Aini Faculty of Medicine, Cairo University, during the period from October 2017 to March 2019. The selection and stratification of the patients were based on sample size calculation and the competence of the availability of the data. A written informed consent was taken from each patient after the nature of the procedure was fully explained. The study protocol was approved by the Ethical Committee of Cairo University. The study protocol conforms to the ethical guidelines of the 1975 Declaration of Helsinki as revised in Brazil 2013.

\section{Methods:}

Patients were subjected to thorough history taking and clinical examination with special emphasis on jaundice, pallor, cachexia, bleeding tendency, ascites, organomegaly and peripheral lymphadenopathy.

Patients were selected between 18 and 75 years, of both sexes, with suspected or proved pancreatic, periampullary masses or GI cancer (detected by ultrasound, CT, MRI or oesophago-gastroduodenoscopy, with or without biopsy).

Patients were excluded if they were below 18 or above 75 years, or pregnant, or suffering from coagulopathies that contraindicate EUS-FNA, or if they were unfit for propofol deep sedation, or those with distant metastases.

The laboratory work up performed included: complete blood count, serum bilirubin (total and direct), AST, ALT, alkaline phosphatase, GGT, serum albumin, prothrombin concentration, serum creatinine, alpha feto protein (AFP) and CA 19-9.

All patients undergone abdominal ultrasound using Toshiba SSA-340A machine with a 3.5MHZ convex linear transducer, with a built in color flow mapping (CFM) and Doppler functions.

All patients were subjected to pancreatic protocol computed tomography scan, which was done using Toshiba Aquilion 64 CT scanner mulitidetector device. Non ionic contrast (Ultravist) was injected at dose $1-2 \mathrm{ml}$ per $\mathrm{Kg}$ with rate $4-5 \mathrm{ml}$ per second. Imaging was done in arterial and venous phases after intravenous injection of contrast. The arterial phase of enhancement, which corresponds to the first 30 seconds after the start of the contrast injection, provided excellent opacification of the celiac axis, superior mesenteric artery, and peripancreatic arteries. The portal venous phase, which was obtained at 60 to 70 seconds after the start of the contrast injection, provided better enhancement of the superior mesenteric vein, splenic and portal veins as well as the pancreas itself and any liver metastases that may be present.

Patients were sent for EUS examination for detection, staging or EUS-FNA for possible neoadjuvant or adjuvant chemotherapy. EUS was done to all patients using an EUS linear array Echoendoscope, Pentax EG-3870UTK attached to Hitachi Avius US machine under propofol deep sedation. During EUS examination, identification of the liver segments was done through the stomach and/or duodenum accordingly. The liver was examined thoroughly to detect hepatic focal lesions with possible EUS-FNA of any detected lesions.

Target lesions were initially identified and their detailed endosonographic features were assessed, then EUS-FNA was carried out using a 22 or 19gauge needles.

\section{Cytological examination:}

The aspirate was spread over glass slides and fixed by $95 \%$ alcohol, also formalin block was provided, then the specimens were subjected to cytological examination, including immunopathological staining if needed.

The final diagnosis was made by the presence of malignant cells in cytological examination.

\section{Statistical analysis:}

Data was entered on the computer using "Microsoft Office Excel Software" program (2010) for windows. Data was then transferred to the Statistical Package of Social Science Software program, version 23 (IBM SPSS Statistics for Windows, Version 23.0. Armonk, NY: IBM Corp.) to be statistically analyzed. 
Data was presented using range, mean, standard deviation median and interquartile range for quantitative variables and frequency and percentage for qualitative ones.

Inter-rater agreement was assessed to estimate the degree of agreement between the studied techniques.

\section{Results}

The demographic features and baseline clinical and laboratory characteristics of the studied patients are summarized in Table (1). From all the studied patients; 53 patients were males $(57.6 \%)$ and 39 were females $(42.4 \%)$, with a mean age of $56.2 \pm$ 12.7 years. The majority of patients presented with nausea and vomiting (77 patients $84 \%$ ), and jaundice (72 patients $78.3 \%$ ). Laboratory data showed markedly elevated AFP level with a range of $536.5 \mathrm{ng} / \mathrm{ml}$, and CA19.9 level with a range of $301.1 \mathrm{mg} / \mathrm{dl}$.

The majority of the studied patients suffered from pancreatic o-biliary tumours (82 patients $89.1 \%$ ), which included pancreatic adenocarcinoma $(81.5 \%)$, papillary maligniancy $(3.3 \%)$ and cholangiocarinoma $(4.3 \%)$. Other presentations included; 5 patients $(5.4 \%)$ with oesophageal adenocarcinoma, 2 patients with gastric adenocarcinoma, and 3 patients with gastro-intestinal stromal tumours (GIST), as shown in Table (2).

Work up done included pancreatic protocol computed tomography scan and endosonography, and revealed that 28 patients (30.4\%) had hepatic focal lesions. These lesions were detected in the right hepatic lobe in four patients, in the left lobe in 11 patients, and bilobar in 13 patients. In 50\% of the patients with detected hepatic focal lesions (14 patients), the focal lesions were small sized $(\leq 2 \mathrm{~cm})$, as shown in Table (3).

On analyzing the results of the pancreatic protocol computed tomography scan, we found that among the 28 patients with hepatic focal lesions, the CT detected the lesions in 27 patients $(96.4 \%)$, where one missed patient was diagnosed by EUS to have a $4 \mathrm{~mm}$ single hypoechoic focal lesion in the left lobe, which proved to be metastatic lesion by EUS -FNA. The CT confirmed that the lesions are metatatic in 16 patients $(57.1 \%)$, and suggested that they are probably metastatic in 11 patients (39.3\%), as shown in Table (4). Among these 11 patients with probably metastatic lesions, four patients were proved by EUS to have cholangitic abcesses.
Table (1): Description of demographic, clinical and laboratory data of studied patients.

\begin{tabular}{|c|c|}
\hline Variables & $\begin{array}{l}\text { Description } \\
(\mathrm{n}=92)\end{array}$ \\
\hline $\begin{array}{l}\text { Age (years): } \\
\quad \text { Mean } \pm \text { SD }\end{array}$ & $56.2 \pm 12.7$ \\
\hline $\begin{array}{l}\text { Gender: } \\
\quad \text { Male, number }(\%)\end{array}$ & $53(57.6 \%)$ \\
\hline $\begin{array}{l}\text { Presentation Number }(\%) \text { : } \\
\text { Jaundice and related symptoms } \\
\text { Cachexia } \\
\text { Nausea and Vomiting } \\
\text { Hepatomegaly } \\
\text { Abdominal pain } \\
\text { Diabetes }\end{array}$ & $\begin{array}{l}72(78.3 \%) \\
57(62 \%) \\
77(84 \%) \\
38(41 \%) \\
61(66 \%) \\
3(3.2 \%)\end{array}$ \\
\hline Hemoglobin $(g / d L)$ : & \\
\hline Mean \pm SD & $13.7 \pm 2.2$ \\
\hline $\begin{array}{l}\text { WBCs } \times 10^{3}\left(\mathrm{cell} / \mathrm{mm}^{3}\right): \\
\text { Mean } \pm \mathrm{SD}\end{array}$ & $10.2 \pm 18.2$ \\
\hline $\begin{array}{l}\text { Platelet count }\left(\mathrm{cell} / \mathrm{mm}^{3}\right) \text { : } \\
\quad \text { Mean } \pm \mathrm{SD}\end{array}$ & $239214.2 \pm 224138.8$ \\
\hline $\begin{array}{l}\text { Total bilirubin }(\mathrm{mg} / \mathrm{dL}) \text { : } \\
\quad \text { Mean } \pm \mathrm{SD}\end{array}$ & $9.2 \pm 1.29$ \\
\hline $\begin{array}{l}\text { Direct bilirubin }(m g / d L) \text { : } \\
\quad \text { Mean } \pm \mathrm{SD}\end{array}$ & $5.85 \pm 1.18$ \\
\hline $\begin{array}{l}\text { Serum ALT (IU/L): } \\
\quad \text { Mean } \pm \text { SD }\end{array}$ & $47.8 \pm 21.5$ \\
\hline $\begin{array}{l}\text { Serum AST (IU/L): } \\
\quad \text { Mean } \pm \text { SD }\end{array}$ & $37.5 \pm 12.2$ \\
\hline $\begin{array}{l}\text { Serum creatinine }(m g / d L) \text { : } \\
\quad \text { Mean } \pm \text { SD }\end{array}$ & $0.88 \pm 0.26$ \\
\hline $\begin{array}{l}A F P(n g / m L): \\
\quad \text { Median (IQR) }\end{array}$ & $536.5(8-4840)$ \\
\hline $\begin{array}{r}\text { CA19-9 }(\mathrm{mg} / \mathrm{dL}): \\
\text { Median (IQR) }\end{array}$ & $301.1(106.7-810.1)$ \\
\hline
\end{tabular}

IQR : Interquantile range

SD : Standard deviation

ALT : Alanine aminotransferase.

AST : Aspartate aminotransferase

AFP : Alpha feto protein.

Data are presented as mean \pm SD, median (Range), or number (\%).

Table (2): Description of primary tumors in studied patients.

\begin{tabular}{lll}
\hline Primary tumors & \multicolumn{2}{c}{$\begin{array}{c}\text { Description } \\
(\mathrm{n}=92)\end{array}$} \\
\hline Pancreatico-biliary: & 82 & $89.1 \%$ \\
Pancreatic Adenocarcinoma & 75 & $81.5 \%$ \\
Papillary malignant mass & 3 & $3.3 \%$ \\
CBD stricture secondary to & 4 & $4.3 \%$ \\
cholangiocarcinoma & & \\
Other GIT malignancies: & 10 & $10.9 \%$ \\
Esophageal adenocarcinoma & 5 & $5.4 \%$ \\
Gastric adenocarcinoma & 2 & $2.3 \%$ \\
GIST & 3 & $3.3 \%$ \\
\hline
\end{tabular}

GIST: Gastro-intestinal stromal tumour. 
Table (3): Description of liver focal lesions of studied cases.

\begin{tabular}{cl}
\hline & $\begin{array}{c}\text { Description } \\
(\mathrm{n}=92)\end{array}$ \\
\hline Presence of liver focal lesions: & \\
Yes & $28(30.4 \%)$ \\
No & $64(69.6 \%)$ \\
Lobe: & \\
Right lobe & $4(14.3 \%)$ \\
Left lobe & $11(39.3 \%)$ \\
Bilobar & $13(46.4 \%)$ \\
Number: & \\
Single & $10(35.7)$ \\
Multiple & $18(64.3)$ \\
Size $($ mm): & \\
Range & $4-70$ \\
Mean \pm SD & $26.9 \pm 16.9$ \\
Median $(\mathrm{IQR})$ & $22.5(15-34.5)$ \\
Size: & \\
Small $(\leq 2 \mathrm{~cm})$ & $14(50)$ \\
Large $(>2 \mathrm{~cm})$ & $14(50)$ \\
\hline
\end{tabular}

Table (4): Description of EUS, EUS-FNA and pancreatic protocol CT scan findings in the studied cases.

\begin{tabular}{ll}
\hline & Description \\
\hline$C T(n=92):$ & \\
$\quad$ Hepatic focal lesion & $27(29.3 \%)$ \\
No hepatic focal lesion & $65(70.7 \%)$ \\
$C T$ diagnosis $(n=28):$ & \\
METs & $16(57.1 \%)$ \\
Probably METs & $11(39.3 \%)$ \\
Missed lesions (detected by EUS FNA) & $1(3.6 \%)$ \\
EUS (n=92): & \\
Hepatic Focal lesion & $27(29.3 \%)$ \\
No hepatic focal lesion & $65(70.7 \%)$ \\
FNA (n=27): & \\
Malignant metastases & $21(77.8 \%)$ \\
Benign focal lesions & $2(7.4 \%)$ \\
Not done & $4(14.8 \%)$ \\
\hline
\end{tabular}

METs: Metastatic lesions.

As regard the EUS findings, the EUS detected hepatic focal lesions in 27 patients $(96.4 \%)$, and one patient was missed $(3.6 \%)$ with a right lobe, single focal lesion, hyperechoic, $25 \mathrm{~mm}$ in size, which was detected by CT scan. Among these 27 patients, EUS-FNA was not performed in four cases (14.8\%) with EUS findings characteristics of cystic lesions in the liver and the patients received antibiotics and follow-up clinically and by trans-abdominal ultrasound confirmed the diagnosis of cholangitic abscesses. The rest of the 23 patients undergone EUS-FNA, and malignant metastatic hepatic focal lesions were confirmed in 21 patients (77.8\%), and two patients (7.4\%) were diagnosed to have focal fat depletion area, as shown in Table (4).
Among the 23 patients who underwent EUS and FNA; there were no $(0 \%)$ minor or major complications during the follow-up period ( 2 weeks) after the procedure.

On assessing the validity of the studied techniques, our results showed that EUS had $95.45 \%$ sensitivity, $97.14 \%$ specificity, $91.3 \%$ positive predictive value (PPV), $98.55 \%$ negative predictive value (NPV) and $96.74 \%$ accuracy. CT had $95.45 \%$ sensitivity, $91.43 \%$ specificity, $77.78 \%$ PPV, $98.46 \%$ NPV and $92.39 \%$ accuracy. And EUSFNA, had $95.45 \%$ sensitivity, $100 \%$ specificity, $100 \%$ PPV, 98.5\% NPV and $98.91 \%$ accuracy, as shown in Table (5).

Table (5): Validity measures of EUS, CT, EUS-FNA.

\begin{tabular}{lcclll}
\hline $\begin{array}{l}\text { Final } \\
\text { diagnosis }\end{array}$ & $\begin{array}{c}\text { Sensi- } \\
\text { tivity }\end{array}$ & $\begin{array}{c}\text { Speci- } \\
\text { ficity }\end{array}$ & PPV & NPV & Accuracy \\
\hline EUS & $95.45 \%$ & $97.14 \%$ & $91.3 \%$ & $98.55 \%$ & $96.74 \%$ \\
CT & $95.45 \%$ & $91.43 \%$ & $77.78 \%$ & $98.46 \%$ & $92.39 \%$ \\
EUS-FNA & $95.45 \%$ & $100 \%$ & $100 \%$ & $98.5 \%$ & $98.91 \%$ \\
\hline
\end{tabular}

\section{Discussion}

Carcinomas that commonly metastasize to the liver include colorectal carcinoma, breast carcinoma, neuroendocrine tumors, lung carcinoma, and gastric carcinoma [10]. Recently, it has been suggested that EUS is a useful tool for detection of liver metastasis [11]. We aimed in this study to assess usefulness of EUS and EUS-FNA in detecting small sized liver metastasis; not diagnosed by CT scan during TMN staging of GI and pancreatic malignancy, which can affect the management plan.

In the current study the mean age of the studied patients was $56.2 \pm 12.7$ years. This matches with the recent global figures, which show that the risk of developing pancreatic and GI cancers increases with age, and most people who develop pancreatic cancer are older than 45 years. The majority of our patients were males $(57.6 \%)$, which matches the higher worldwide incidence of pancreatic cancer in males than females [12].

In terms of characteristics of the detected focal hepatic lesions, our results showed that the majority of the lesions were multiple and bilobar; and half of them were larger than $2 \mathrm{~cm}$. This is explained by the fact that most liver metastases are multiple. Multiple tumors often vary in size; this is because tumor seeding occurs in episodes [13]. 
In the present study, the EUS yielded a sensitivity of $95.45 \%$ and a specificity of $97.14 \%$, while CT scan yielded a sensitivity of $95.45 \%$, a specificity of $91.43 \%$ for the detection of small-sized liver metastasis. EUS showed a slightly higher diagnostic accuracy $(96.7 \%)$ for detecting smallsized liver metastasis, compared to that of CT scan $(92.4 \%)$. One case with liver metastatic lesion was missed by EUS, and one case was missed by CT scan. Although, this difference in accuracy is statistically small, yet practically, it is a significant difference, and warrants further studies on a larger sample.

In concordance with our findings, Singh et al., [14] compared the accuracy of the EUS/EUS-FNA with CT scan for detection of the liver metastases. The diagnostic accuracy of EUS/EUS-FNA was higher than CT scan (98\% and 92\%, respectively).

However, Nguyen et al., [15] work showed a more significant superiority of EUS over CT scan for diagnosis liver metastatic lesions. They studied 574 patients with history or suspicion of gastrointestinal or pulmonary malignant tumor. Fourteen (2.4\%) patients were found to have focal liver lesions by EUS; while the CT detected liver lesions in only 3 of the 14 (21\%) patients. Thus, the diagnostic yield of EUS was significantly higher than CT. This more obvious difference between CT scan and EUS compared to our study, may be explained by the larger sample size in Nguyen et al., study, and by the enrollment of patients with pulmonary malignant tumors; who were not included in our study.

Regarding the diagnostic accuracy of EUSFNA, EUS-FNA was performed in 23 patients who were identified with definite liver lesions. It had a sensitivity of $95.45 \%$, specificity of $100 \%$, PPV of $100 \%$, NPV of $98.5 \%$ and a diagnostic accuracy of $98.91 \%$.

This matches with the results of Ichim et al., [16], who conducted a systematic review in order to assess the evidence supporting the diagnostic yield of endoscopic ultrasound-guided biopsy of focal liver lesions (9 studies included), and concluded that endoscopic ultrasound-guided biopsy proved to be superior to CT scan in diagnostic accuracy ( $98 \%$ versus $82 \%$ ).

Also in agreement with our findings, Hollerbach et al., [17] conducted a prospective study on 41 patients with clinical findings suggestive of liver malignancies. The EUS-FNA had a sensitivity of $94 \%$ and specificity of $100 \%$, with a negative predictive value of $78 \%$ and positive predictive value of $100 \%$

In contrast to our study, the work done by FujiiLau et al., [9] over a 12-year period, and studied 332 patients, showed much lower EUS-FNA diagnostic accuracy in comparison to our study. EUSFNA of a hepatic mass had a diagnostic accuracy of $73 \%$ and a positive predictive value of $88 \%$. The exact causes of such heterogeneities in results between both studies are unclear. However, it can be attributed to difference in sample size, study design, or level of experience of investigators who performed EUS-FNA.

As regard the safety of the procedure, none of our patients suffered from major or minor complications during the procedure, during the followup period ( 2 weeks) after the procedure.

This matches with the work done by DeWitt et al., 2004 [18], who performed EUS-FNA from 77 liver lesions in 77 patients, and no complications were reported.

\section{Conclusion and recommendations:}

In conclusion, EUS and EUS-FNA play a significant role in detecting small sized liver metastasis, and differentiating it from benign lesions, during TMN staging of GI and pancreatic malignancy, where EUS and EUS-FNA showed a slightly higher diagnostic accuracy compared to that of CT scan.

\section{Study's Limitations:}

We report that the present study had some limitations. These limitations included the relatively small sample size, in addition to the high cost of the procedure, as well as the cost of the needles used in EUS-FNA technique.

\section{Declaration of interest:}

- The authors declare no conflict of interest.

- There is no source of funding.

\section{References}

1- SRINIVASAN I., TANG S.J., VILMANN A.S., MENACHERY J. and VILMANN P.: Hepatic applications of endoscopic ultrasound: Current status and future directions. World J. Gastroenterol., 21: 12544-57, 2015.

2- ROSENBLUM J.D., BOYLE C.M. and SCHWARTZ L.B.: The mesenteric circulation: Anatomy and physiology. Surg. Clin. North Am., 77: 289-306, 1997.

3- SIMARD E.P., WARD E.M., SIEGEL R. and JEMAL A Cancers with increasing incidence trends in the United States: 1999 through 2008. CA Cancer J. Clin., 62: 118$128,2012$. 
4- FIORENTINI G., SARTI D., ALIBERTI C., CARANDINA R., MAMBRINI A. and GUADAGNI S.: Multidisciplinary approach of colorectal cancer liver metastases. World J. Clin. Oncol., 8 (3): 190-202, 2017.

5- SHIN A., KIM J. and PARK S.: Gastric cancer epidemiology in Korea. J. Gastric Cancer, 11: 135-140, 2011.

6- WONG J.Y.Y., KONGKAM P. and HO K.Y.: Training in endoscopic ultrasonography: An Asian perspective. Dig. Endosc., 29: 512-6, 2017.

7- RAMESHBABU C.S., WANI Z.A., RAI P., ABDULQADER A., GARG S. and SHARMA M.: Standard imaging techniques for assessment of portal venous system and its tributaries by linear endoscopic ultrasound: A pictorial essay. Endosc. Ultrasound, 2: 16-34, 2013.

8- PAREKH P.J., MAJITHIA R., DIEHL D.L. and BARON T.H.: Endoscopic ultrasound-guided liver biopsy. Endosc. Ultrasound, 4: 85-91, 2015.

9- FUJII-LAU L.L., ABU DAYYEH B.K., BRUNO M.J., CHANG K.J., DeWITT J.M., FOCKENS P., et al.: EUSderived criteria for distinguishing benign from malignant metastatic solid hepatic masses. Gastrointest Endosc., 81: 1188-1196, 2015.

10-PARK J.H. and KIM J.H.: Pathologic differential diagnosis of metastatic carcinoma in the liver. Clinical and Molecular Hepatology, 25 (1): 12-20, 2019.

11-GIROTRA M., SOOTA K., DHALIWAL A.S., GARCIASAENZ-DE-SICILIA M. and THARIAN B.: Utility of endoscopic ultrasound and endoscopy in diagnosis and management of hepatocellular carcinoma and its complications: What does endoscopic ultrasonography offer above and beyond conventional cross-sectional imaging? World J. Gastrointest Endosc., 10 (2): 56-68, 2018.

12- American Cancer Society. Key Statistics for Pancreatic Cancer, 2018.

13-HEYDE A., REITER J.G., NAXEROVA K. and NOWAK M.A.: Consecutive seeding and transfer of genetic diversity in metastasis. PNAS, 116 (28): 14129-37, 2019.

14- SINGH P., MUKHOPADHYAY P., BHATT B., PATEL T., KISS A. and GUPTA R.: Endoscopic ultrasound versus CT scan for detection of the metastases to the liver: Results of a prospective comparative study. J. Clin. Gastroenterol., 43: 367-73, 2009.

15- NGUYEN P., FENG J.C. and CHANG K.J.: Endoscopic ultrasound (EUS) and EUS-guided fine-needle aspiration (FNA) of liver lesions. Gastrointestinal Endoscopy, 50 (3): 357-61, 1999.

16- ICHIM V.A., CHIRA R.I. and MIRCEA P.A.: Diagnostic yield of endoscopic ultrasound-guided biopsy of focal liver lesions. Medicine and Pharmacy Reports, 92 (1): 15-20, 2018.

17- HOLLERBACH S., WILLERT J., TOPALIDIS T., REISER M. and SCHMIEGEL W.: Endoscopic ultrasoundguided fine-needle aspiration biopsy of liver lesions: Histological and cytological assessment. Endoscopy, 35 (9): 743-9, 2003.

18- DeWITT J., LeBLANC J., McHENRY L., CIACCIA D., IMPERIALE T., CHAPPO J., et al.: Endoscopic ultrasound-guided fine needle aspiration cytology of solid liver lesions: A large single-center experience. Amer J. Gastroenterology, 98 (9): 1976-81, 2004. 


\section{دور التثظير الداخلى بالموجات فوق الصوتية وسحب الخخلايا من خلال إبرة رفيعة

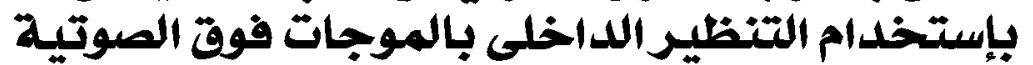

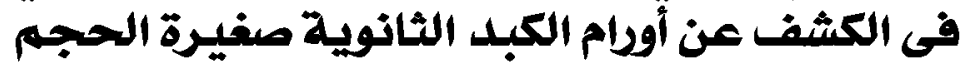

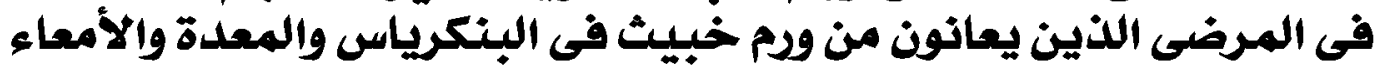

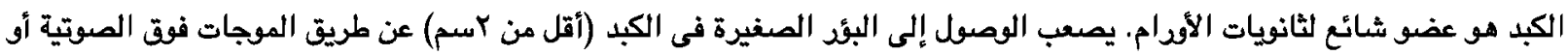

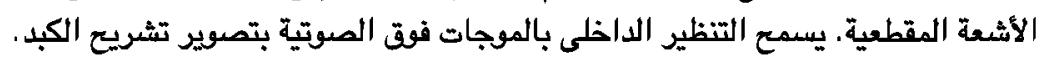

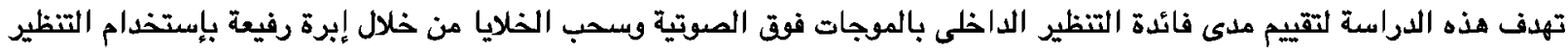

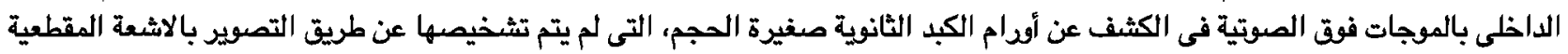

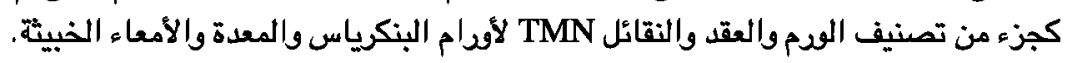

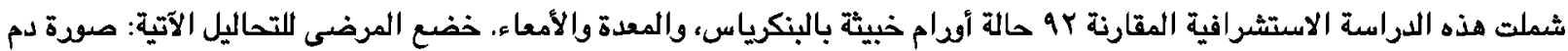

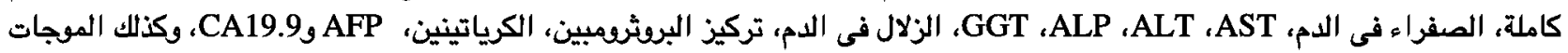

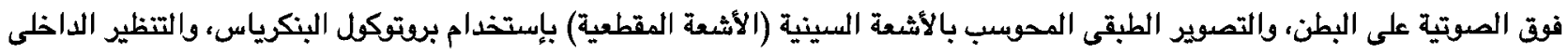
بالموجات فوق الصوتية. تم إجراء الشفط بإبرة رفيعة بإستخدام التنظير الداخلى بالموجات فوق الصوتية والفحص الخلمى للعينات بالنسبة נلr مريض.

أكتشفت الأشعة المقطعية وجود بؤد فى كبد في كV حالة، وأغفلت التشخيص فى مريض واحد. بينما أكتشف التظير الداخلى بالموجات

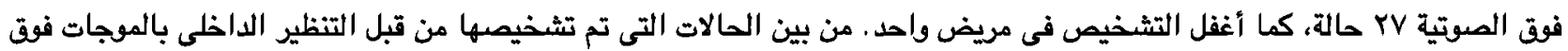

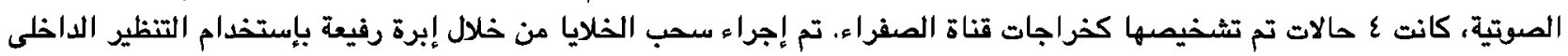

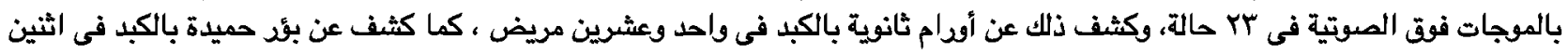

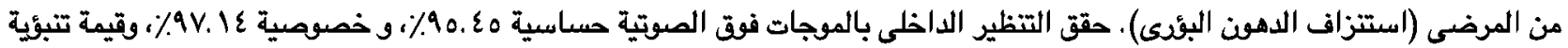

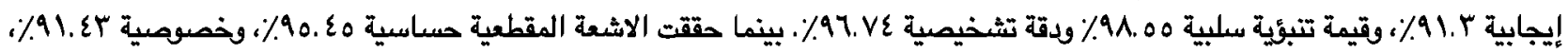

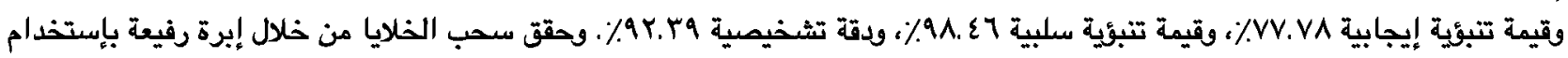

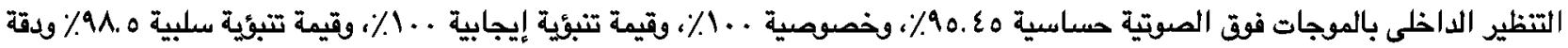

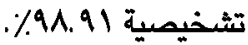

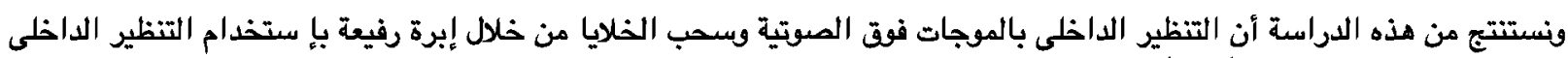

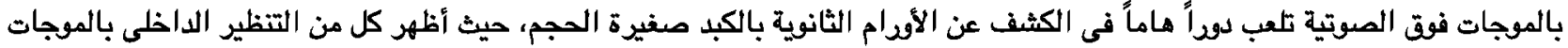

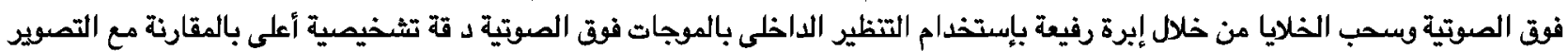

